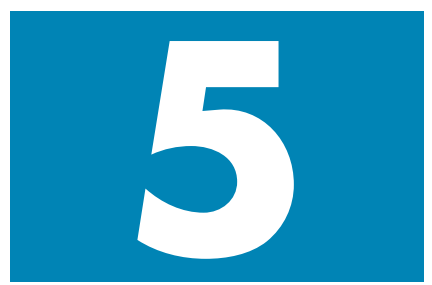

\title{
Gathering information 2: methods of assessment
}

\author{
M. Grace'
}

\section{The SEQ provides people with the opportunity to distinguish between knowledge and ability in themselves in all the relevant areas in order to achieve the business objectives.}

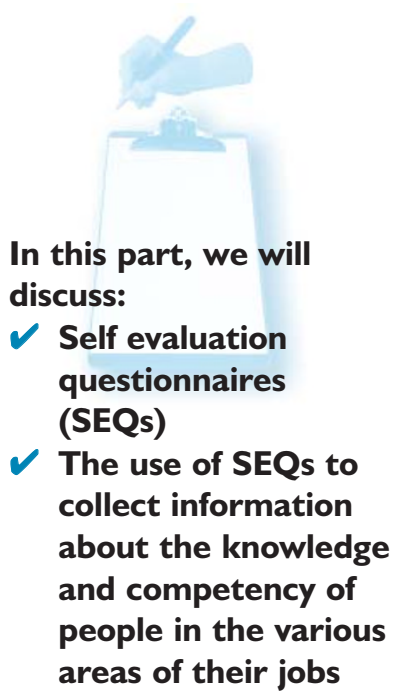

${ }^{1}$ Editor, British Dental Journal, 64 Wimpole Street, London W1G $8 Y$ S ${ }^{*}$ Correspondence to: Mike Grace email:m.grace.bdj@bda-dentistry.org.uk REFEREED PAPER

(C) British Dental Journal 2001; 191: 11-18
$I^{3}$ the previous part in the series we looked at simple methods of obtaining information that are useful in analysing the areas where gaps in knowledge and skills would require some form of training in order for people to carry out their jobs more effectively. Most of this information was available because of other procedures the practice carried out (such as job descriptions and appraisals) but there are some specific things you can do to identify training needs as well. This article is about two of the most common in small businesses and dental practices: self evaluation questionnaires and interviews.

\section{Self evaluation forms}

Self evaluation questionnaires (SEQs) are extremely useful forms you can use to collect information about how knowledgeable and competent people think they are in various areas of their job.

Figure 1 is an example of such a form. The form can be used for virtually any member of staff, has a number of generic areas in customer care, and asks the person completing the form to assess their level of competence by marking the form with either one, two or three 'blobs' (circles) in each of the boxes under the headings of 'Ability' and 'Knowledge'. Figure 2 shows the form completed.

\section{Choosing the subjects}

Figure 1 shows a number of subjects in the list that have been collected under the overall title of 'Customer care'. How were they chosen?

There are two main methods of selecting appropriate topics to ask people to assess themselves on:

1. What they need to do (their job description)

2. What you want to happen

In this case customer care is obviously part of everyone's job, but it can be easier to identify the areas required by thinking of what we want to happen in the organisation. Figure 1 contains one example of such a list.

What we must always remember is that the SEQs must have some relevance to the business objectives of the practice. Often these are obvious (after all, every service business should be concerned with customer care) but you may choose to select those subjects that are an especially important priority at the time (such as attracting new patients when applicable or increasing profitability at a time of financial concern). That way you can tailor the SEQs to different areas that are genuinely important at the moment, thus making the TNA more effective.

The choice of topics should be the responsibility of the person involved in overall training, obviously in discussion with senior management (the dentist in most dental practices) and should reflect the current priorities and direction of the practice.

It is not necessary to give everyone in the organisation exactly the same SEQ to complete. Sometimes very specific forms for each person will result in better data to analyse. However, it is important to make sure that the person responsible for the TNA knows that, at this stage, the exercise is to simply collect the information, not to analyse it. The analysis comes later.

\section{Ability and knowledge}

The upper section of the questionnaire is selfexplanatory, and asks the person completing the SEQ to use a grading scale of blobs (these forms are often known as the 'blobby charts' by the participants). The wording should make it apparent how to grade oneself.

However, people are asked to grade both their knowledge and ability, and this can cause some confusion initially. For this reason it can be sensible to make sure that SEQs are given to people with an explanation of how to distinguish between knowledge and ability. To help in that explanation, the next few paragraphs examine this difference.

Some people are very good at doing certain things, sometimes with very little knowledge of how they do them or why they are good. They are naturally good. While their ability may be very good (three blobs) they would not be able to train others easily because they do not understand what they are doing, they simply do it. Conversely other people are very knowledgeable about certain things but find them difficult to do.

An example of the first situation could be a receptionist who is excellent at negotiating appointments with patients, or very good at communicating over the telephone. Everyone knows she is good at this, but she does 
not know why she is successful. To her everything she does is obvious, and observation may help someone else to improve but quite often will not be very effective because the receptionist feels very comfortable doing whatever she does while a new member of staff is simply not able to do the same thing. People often think or say 'I am not like you' resulting in poor performance in the 'softer' skills such as communication, negotiation and so on.

An example of the second situation could be a dentist who knows everything there is to know about endodontics, but simply cannot seem to practice root-filling molars as well as he should. He has attended a number of postgraduate courses, has bought a number of books, and continues to ask colleagues how to

\section{Fig. I A self evaluation questionnaire for any member of staff on customer care}

\section{Customer Care Self -Evaluation Questionnaire}

\section{For:} (name of person)

Please read the questions below and select the option that most accurately reflects how you feel.

KEY

Using the following system please fill in the 'ability' and 'knowledge' boxes below.
- I don't feel I know a lot/I am not confident I achieve this
- - I feel my knowledge is adequate/l am reasonable at achieving this
$\bullet \bullet$
I feel my knowledge is (very) good/l am good at achieving this

\section{CUSTOMER CARE}

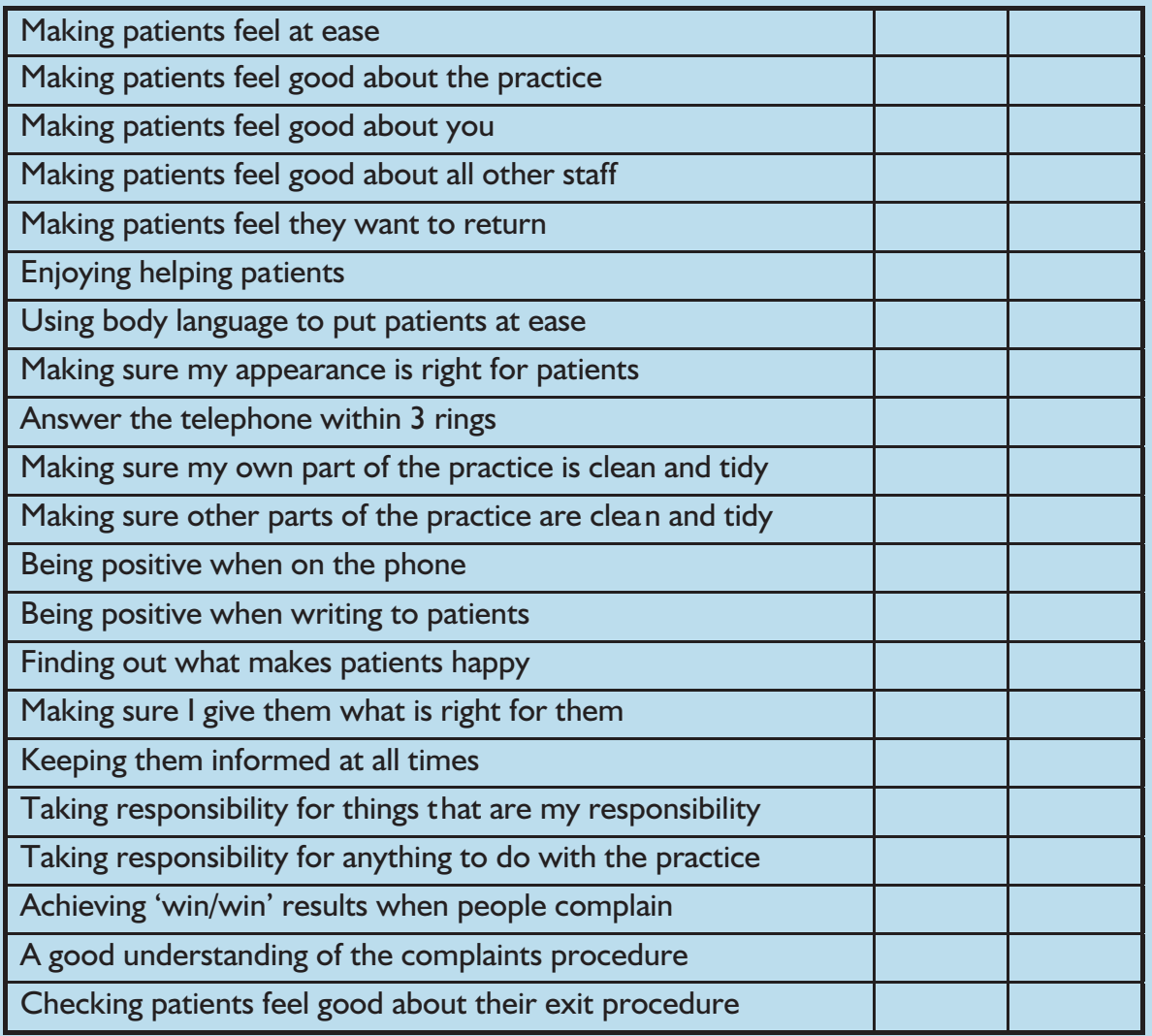


improve. His knowledge is more than adequate, but his ability is just not good enough (for whatever reason).

The SEQ provides people with the opportunity to distinguish between knowledge and ability in themselves in all the relevant areas in order to achieve the business objectives.

Another example is shown in Figure 3 where the practice manager has marked the SEQ to show that she feels she is very knowledgeable in making patients feel good about her and enjoys helping them, but interestingly her knowledge is poor in making patients feel good about other staff, in making patients want to return and in using body language. She has also recognized a lack of knowledge in making patients feel at ease and making patients feel good about the practice (one

\section{Fig, 2 A self evaluation questionnaire completed by the practice manager}

\section{Customer Care Self-Evaluation Questionnaire}

For: SUSIE KEW (name of person)

Please read the questions below and select the option that most accurately reflects how you feel.

KEY

Using the following system please fill in the 'ability' and 'knowledge' boxes below.

- I don't feel I know a lot/I am not confident I achieve this

- I feel my knowledge is adequate/l am reasonable at achieving this

- - I feel my knowledge is (very) good/l am good at achieving this

\section{CUSTOMER CARE}

\begin{tabular}{|l|c|c|}
\hline Making patients feel at ease & $\bullet$ & \\
\hline Making patients feel good about the practice & $\bullet$ & \\
\hline Making patients feel good about you & $\bullet$ & \\
\hline Making patients feel good about all other staff & $\bullet$ & $\bullet$ \\
\hline Making patients feel they want to return & $\bullet$ & $\bullet$ \\
\hline Enjoying helping pa tients & $\bullet$ & $\bullet$ \\
\hline Using body language to put patients at ease & $\bullet$ & $\bullet$ \\
\hline Making sure my appearance is right for patients & $\bullet$ & $\bullet$ \\
\hline Answer the telephone within 3 rings & $\bullet$ & $\bullet$ \\
\hline Making sure my own part of the practice is clean and tidy & $\bullet$ & $\bullet$ \\
\hline Making sure other parts of the practice are clean and tidy & $\bullet$ & $\bullet$ \\
\hline Being positive when on the phone & $\bullet$ & $\bullet$ \\
\hline Being positive when writing to patients & $\bullet$ & $\bullet$ \\
\hline Finding out what makes patients happy & & $\bullet$ \\
\hline Making sure I give them what is right for them & $\bullet$ & $\bullet$ \\
\hline Keeping them informed at all times & $\bullet$ & $\bullet$ \\
\hline Taking responsibility for things that are my responsibility & $\bullet$ & $\bullet$ \\
\hline Taking responsibility for anything to do with the practice & $\bullet$ & $\bullet$ \\
\hline Achieving 'win/win' results when people complain & $\bullet$ & $\bullet$ \\
\hline A good understanding of the complaints procedure & $\bullet$ \\
\hline Checking patients feel good about their exit procedure & $\bullet$ \\
\hline
\end{tabular}

(C) UMD Professional Ltd 


\section{Fig. 3 The top part of the SEQ}

CUSTOMER CARE

Making patients feel at ease

Making patients feel good about the practice

Making patients feel good about you

Making patients feel good about all other staff

Making patients feel they want to return

Enjoying helping pa tients

Using body language to put patients at ease

Malina rum mu annonmanan is riaht fan mationte

Ability Knowledge

\begin{tabular}{|c|c|}
\hline$\bullet \bullet$ & $\bullet$ \\
\hline$\bullet \bullet$ & $\bullet$ \\
\hline$\bullet$ & $\bullet \bullet$ \\
\hline$\bullet$ & $\bullet$ \\
\hline$\bullet$ & $\bullet$ \\
\hline$\bullet \bullet \bullet$ & $\bullet \bullet \bullet$ \\
\hline$\bullet$ & $\bullet$ \\
\hline
\end{tabular}

(c) UMD Professional Ltd

\section{Fig. 4 The SEQ showing how to mark a section that is not relevant}

\begin{tabular}{|c|c|c|}
\hline & & \\
\hline Being positive when on the phone & $\bullet \bullet \bullet$ & $\bullet$ \\
\hline Being positive when writing to patients & 0 & $\bullet$ \\
\hline Finding out what makes patients happy & $\bullet$ & ○ \\
\hline Making sure I give them what is right for them & N/A & N/A \\
\hline Keeping them informed at all times & $\bullet$ & $\bullet$ \\
\hline
\end{tabular}

(c) UMD Professional Ltd

blob) but has the ability to achieve this adequately (two blobs). In other words, she seems to recognize she achieves these last two points without quite knowing why.

Figure 4 shows what happens when the person completing the form does not feel the area on the form is relevant. In this case she may have interpreted this as providing clinical treatment and has rightly regarded this as inappropriate. She might be right, or the person writing the form may have intended this question to refer to non-clinical aspects such as making appointments or answering the telephone. This kind of mistake can easily be rectified (if this was the case) by explaining the misunderstanding and by asking her to complete the relevant section. Often this situation is very useful in clarifying areas of someone's job that might have been unclear.

\section{Benefits of SEQs}

Besides obviously helping to identify training needs, SEQs have been found to have a number of other benefits.

Firstly they improve communication within the organisation because people have to discuss areas of confusion in their jobs and possible confusion in the expectations of the manager and the person being managed. An SEQ can be very useful in performance review (appraisal) to help clarify matters.

Secondly, SEQs make staff feel that someone is genuinely interested in their development. This helps in motivation as well as increased or improved performance. People are always happier if they think management want to help them improve themselves, for the benefit of both the business and themselves.

Another advantage is the increased communication that SEQs foster, because people have a reason to talk about things with each other rather than simply keeping the 'head down get on with the job' attitude that tends to stifle communication.

Lastly, SEQs imply that you are giving people a lot of involvement in their own training and development, and that creates a feeling of trust and respect. Providing SEQs are actioned appropriately (in other words the findings are not simply ignored) they are obviously a great motivator.

\section{Other areas}

In this chapter I have focused on a SEQ that focuses on customer care. Other areas that are usually very relevant are clinical areas, management generally and administration. Figures 5 and 6 show some more examples. 


\section{Interviews}

The term 'interview' has a formality about it that is probably inappropriate for a TNA. Many organisations carry out performance reviews already in the form of appraisals, while informal 'get togethers' can be very effective. Thus the term 'interview' really refers to any method of communication between a manager and another member of staff where the emphasis of the conversation is on training and development.

Thus you may find that your appraisal already collects enough information on an individual's training needs for this to be suffi-

\section{Fig. 5 An SEQ on clinical topics}

\section{Clinical Self -Evaluation Questionnaire}

For: (name of person)

Please read the questions below and select the option that most accurately reflects how you feel.

Using the following system please fill in the 'ability' and 'knowledge' boxes below.

- I don't feel I know a lot/I am not confident I achieve this

- I feel my knowledge is adequate/l am reasonable at achieving this

- I feel my knowledge is (very) good/l am good at achieving this

\begin{tabular}{|l|l|l|}
\hline Taking a medical history & & \\
\hline Full mouth examination & & \\
\hline Periodontal examination & & \\
\hline Periodontal monitoring & & \\
\hline Oral cancer check & & \\
\hline Use of local anaesthetic & & \\
\hline Reviewing radiographs & & \\
\hline Treatment planning & & \\
\hline Oral hygiene instruction & & \\
\hline Patient motivation & & \\
\hline Scaling and maintenance & & \\
\hline Root planing & & \\
\hline Cavity preparation & & \\
\hline Placement of amalgam restorations & & \\
\hline Placement of anterior restorations & & \\
\hline Crown preparation & & \\
\hline Bridge preparation & & \\
\hline Endodontic treatment & & \\
\hline Taking impressions for advanced work & & \\
\hline Occlusal adjustment & & \\
\hline Construction of complete dentures & & \\
\hline Construction of partial dentures (acrylic) & & \\
\hline Construction of partial dentures (metal) & & \\
\hline Orthodontic diagnosis and evaluation & & \\
\hline Treating children & & \\
\hline Implants & & \\
\hline First aid procedures & & \\
\hline Communication skills & & \\
\hline Cross infection control procedures & \\
\hline Keeping up to date with new techniques & & \\
\hline
\end{tabular}




\section{Fig. 6 An SEQ on general management topics}

\section{Management Self -Evaluation Questionnaire}

For: (name of person)

Please read the questions below and select the option that most accurately reflects how you feel.

Using the following system please fill in the 'ability' and 'knowledge' boxes below.

- I don't feel I know a lot/I am not confident I achieve this

- I feel my knowledge is adequate/l am reasonable at achieving this

- I feel my knowledge is (very) good/l am good at achieving this

MANAGEMENT
\begin{tabular}{|l|l|l|}
\hline Prepare a I0 year strategic plan & & \\
\hline Prepare a 2-year strategic plan & & \\
\hline Carry out a SWOT analysis & & \\
\hline Set SMART objectives & & \\
\hline Delegate to staff & & \\
\hline Monitor and evaluate individual performance & & \\
\hline Organise and prioritise own workload & & \\
\hline Time management & & \\
\hline $\begin{array}{l}\text { Create and maintain effective relationships with } \\
\text { staff }\end{array}$ & & \\
\hline $\begin{array}{l}\text { Create and maintain effective relationships with } \\
\text { patients }\end{array}$ & & \\
\hline Manage stress & & \\
\hline Manage customer care & & \\
\hline Solve problems & & \\
\hline Run effective practice meetings & & \\
\hline Plan on a day-to-day basis & & \\
\hline Awareness of health and safety & & \\
\hline Maintain quality of service & & \\
\hline
\end{tabular}

ADMINISTRATIVE
\begin{tabular}{|l|l|l|}
\hline Making an appointment for a patient & & \\
\hline Setting up office management systems & & \\
\hline Using the filing system & & \\
\hline Organising the recall system & & \\
\hline Typing a business letter & & \\
\hline Using a Dictaphone & & \\
\hline Writing a referral letter & & \\
\hline Keyboard skills on computer & & \\
\hline Knowledge and use of word processing & & \\
\hline Knowledge and use of spreadsheets & & \\
\hline Sending an e-mail & & \\
\hline Using the internet & & \\
\hline
\end{tabular}

Table continued

(c) UMD Professional Ltd 


\section{Fig. 6 contd An SEQ on general management topics}

MARKETING
\begin{tabular}{|l|l|l|}
\hline Carry out market research & & \\
\hline Analyse market research findings & & \\
\hline Promote the practice & & \\
\hline Design advertisements & & \\
\hline Place advertisements & & \\
\hline Design brochures & & \\
\hline Write a mailshot letter & & \\
\hline Implement a mailshot & & \\
\hline Understand market segmentation & & \\
\hline Write a press release & & \\
\hline Use public relations methods & & \\
\hline Selling skills & & \\
\hline Price various services & & \\
\hline Improve profitability & & \\
\hline
\end{tabular}

\section{FINANCIAL}

Ability Knowledge

\begin{tabular}{|l|l|l|}
\hline Location of financial paperwork & & \\
\hline Types and use of financial paperwork & & \\
\hline Location of current price information & & \\
\hline Processing of payment (cash/cheque) & & \\
\hline Processing a credit card payment & & \\
\hline Book keeping & & \\
\hline Location and use of account system & & \\
\hline Location and use of petty cash system & & \\
\hline Requesting payment at the end of each & & \\
\hline Discussing fees with patient & & \\
\hline Setting prices & & \\
\hline Understanding a balance sheet & & \\
\hline Understanding a profit/loss statement & & \\
\hline Being able to do a cash flow forecast & & \\
\hline Understanding the principles of working capital & & \\
\hline Understanding how depreciation works & & \\
\hline
\end{tabular}

(c) UMD Professional Ltd

cient, and apart from carrying out a self assessment using an SEQ first there is no need to have a further interview. Alternatively you may find that an interview held midway between annual appraisals is a very good way of keeping contact in a formal way. The solution is to use the method that is most suitable for you.

In terms of training and development the interview (whenever and however it is held) should focus on the ability of the individual to carry out his or her job as effectively as possible, on possible future developments that may create the need for training, and on concerns of that individual. There is no ideal fixed format, although a few questions on a simple form will help. This is especially useful for the interviewee, because he or she can be given the form in advance to help stimulate ideas and prevent undue concern about the kinds of questions to be asked or topics to be discussed.

Some basic guidelines for interviews are:

1. Keep the questions simple and ideally use open questions (questions with who, what, where, how and why) rather than closed questions (questions that only require 'yes' or 'no' for an answer).

2. Let the interviewee see the questions in advance.

3. Select a time and place where both interviewer and interviewee will not be disturbed.

4. Use the questions as a stimulus for the answer rather than a strict control over the interview.

5. The interviewer should write down a sum- 
mary of the answer and ask the interviewee to agree it is correct.

6. Do not have too many questions (ideally 6-10 maximum).

7. If appropriate allow different people to do the interviewing (preferably with training rather than simply ad hoc).

8. Respect confidentiality.

With larger organisations a more formal approach may well be preferable, especially as people need to feel treated fairly. In smaller practices a more informal approach (but still with written answers) should be sufficient. If the interview is part of a larger appraisal then obviously it can be incorporated into the appraisal form and only this section transferred to the person doing the training needs analysis.

\section{Conclusion}

Both self evaluation questionnaires (SEQs) and interviews can be very helpful as part of a training needs analysis. Neither should be very timeconsuming (an SEQ should typically take 5 minutes to complete per form, and interviews of over 10 minutes are probably excessive). Both will add information to other paperwork collected to help provide a more comprehensive body of data to analyse in the next section of the process, which forms the content of the next part in the series. 